\title{
OS ESTADOS UNIDOS, A REVOLUÇÃO CUBANA E A CONTRA-INSURREIÇÃO'
}

\author{
João Roberto Martins Filho \\ Universidade Federal de São Carlos
}

\section{RESUMO}

Este artigo estuda o impacto da Revolução Cubana sobre as relações interamericanas entre 1959 e 1964 e, especificamente, a herança deixada pela teoria da contra-insurreição, exportada com entusiasmo durante o governo Kennedy. Nesse período, a América Latina figurou com destaque na pauta do Departamento de Estado e do Pentágono, o que se expressou na multiplicação da ajuda militar americana e no reforço do papel anti-subversão, historicamente desempenhado pelos militares da área. Ao contrário, nos próprios Estados Unidos, o emprego das chamadas Forças Especiais foi problemático, gerando resistências e tensões dentro das Forças Armadas.

PALAVRAS-CHAVE: América Latina; Revolução Cubana; governo Kennedy; contra-insurreição; ajuda militar.

\section{INTRODUÇÃO}

Agosto de 1961. No discurso que dirige aos delegados do Conselho Econômico e Social Interamericano, reunidos na cidade uruguaia de Punta del Este, quatro meses depois do fracasso da invasão da Baía dos Porcos, o ministro cubano Ernesto "Che" Guevara toca num ponto sensível. Ao denunciar que sem a vitória da Revolução Cubana não existiria a festejada "Aliança para o Progresso" - o programa do recém-eleito Presidente John Kennedy para o desenvolvimento econômico e social da América Latina —, Guevara registrava uma vinculação historicamente

\footnotetext{
1 Este artigo foi escrito para o seminário sobre os trinta anos da morte de Ernesto "Che" Guevara, organizado pelo professor João Quartim de Moraes no Instituto de Filosofia e Ciências Humanas da UNICAMP em 9 de outubro de 1997. É resultado parcial de pesquisa realizada junto ao Centro de Estudos Latino-Americanos da Universidade da Califórnia, Los Angeles, dirigido por Carlos Alberto Torres. Sou grato aos funcionários da Biblioteca do Congresso, em Washington. Na Califórnia, James Green, Ron e Fran Chilcote, Gary Hytrek e Jayne Spencer me acolheram com suas sugestões e amizade. Ken Serbin, então no Brasil, ajudoume à distância. A FAPESP financiou a viagem aos EUA como parte do projeto As Forças Armadas brasileiras e o fim da Guerra Fria: segurança e defesa (Programa "Jovem Pesquisador em Centros Emergentes"), que desenvolvo no Departamento de Ciências Sociais da UFSCar.
}

verdadeira (cf. CASTAÑEDA, 1997, p. 238-245). Sem a Cuba de Fidel, a América Latina continuaria no último plano das preocupações políticas e estratégicas dos Estados Unidos nos quadros da Guerra Fria. A partir de 1959 e até 1964, quando o Vietnã passou a monopolizar as atenções americanas, o subcontinente figurou com destaque na pauta do Departamento do Estado e do Pentágono. Os sinais dessa nova importância já eram evidentes no último ano do governo Eisenhower e, não por acaso, Ike reivindicou posteriormente a paternidade da "Aliança" (cf. RABE, 1988, p. 149).

Essa súbita valorização deu-se no clima geral de ativismo que tomou conta da Casa Branca, com a ascensão de uma nova geração de militantes da Guerra Fria, prontos a provar que podiam recuperar o terreno perdido para a União Soviética no conflito global do final dos anos cinqüenta. Assim, se na política interna (a "Nova Fronteira"), a década democrata efetivamente deixou sua marca de mudança - no avanço do Welfare State e dos direitos civis - , na política externa de Kennedy transparecem os princípios básicos da cultura da Guerra Fria. Tudo que se relacionava a Kennedy parecia novo: o "Grande Projeto" europeu, a "Nova África", a "Aliança para o Progresso", a "Resposta Flexível", a "Guerra Especial” ou a "Contra-Insurreição". Vistas à distância, porém, aquelas iniciativas soam hoje apenas como mais uma das injeções de energia americana no conflito bipolar 
com os soviéticos, típica da manipulação da Guerra Fria para os fins da dinâmica eleitoral dos Estados Unidos (cf. PATERSON, 1988, p.198-199)2

Neste artigo, pretendo analisar as conseqüências do ativismo kennedyano - sob o impacto da Revolução Cubana - no campo das relações militares interamericanas. Mais especificamente, procuro mostrar aqui como a ascensão do ideário da contra-insurreição refletiu-se num significativo aumento nas dimensões daquilo que se convencionou chamar de "ajuda militar" dos EUA aos países da América Latina - ao mesmo tempo que lhe fornecia uma função clara e sem contradições.

$\mathrm{Na}$ terminologia da Guerra Fria, esse aspecto da hegemonia americana foi batizado de "Defesa do Hemisfério" e seu canal de implementação definido no início dos anos cinqüenta — era o Programa de Ajuda Militar (PAM) para a América Latina. Formou-se, assim, por meio de inúmeros acordos militares bilaterais, o chamado Sistema Interamericano de Defesa ${ }^{3}$. Embora sob o disfarce ideológico da "Defesa Mútua" ou "Auto-Defesa Coletiva", tratava-se da simples extensão da política de defesa nacional dos EUA a seus vizinhos mais fracos do Sul. Nas palavras de um documento americano dos final dos anos cinqüenta: "A segurança dos Estados Unidos é o mesmo que a segurança do Hemisfério" (RABE, 1988, p. 23). Nesse quadro, nosso propósito é mostrar como a resposta americana à revolução em Cuba configurou-se numa nova ênfase estratégica - a "contra-insurreição" - sob cujo signo a aliança militar interamericana ganhou fôlego e recursos, durante um curto espaço de tempo. A partir dos problemas no Vietnã e dos decorrentes obstáculos colocados pelo Congresso americano depois de 1967, a ajuda militar entrará em crise. Mas, a essa altura, mais de uma dúzia de países latino-americanos já era governada por ditaduras castrenses, cuja ação foi profundamente marcada pelas concepções anti-insurrecionais durante todo os anos setenta.

\footnotetext{
2 Para uma excelente crônica do governo Kennedy, ver HALBERSTAM, 1992.
3 Para a formação da política de "ajuda militar" americana no pós-Segunda Guerra, ver HOVEY, 1966, cap. IV. Considerações mais gerais sobre o uso político das Forças Armadas aparecem em BLECHMAN e KAPLAN, 1978, p. $1-20$.

\section{A AJUDA MILITAR NOS ANOS CINQÜENTA}

O Sistema Militar Interamericano tem suas origens na Segunda Guerra Mundial e suas bases estabelecidas nas conferências do Rio de Janeiro (1942) e Chapultepec (México, 1945). Com o fim da guerra, uma série de encontros secretos entre os chefes militares americanos e seus colegas latinos deixou claro o interesse geral na manutenção da aliança militar do período 1942-45. Aos EUA interessavam conservar as bases militares da fase da guerra e o monopólio de matérias-primas de valor estratégico, bem como a exclusividade do fornecimento de armas. Depois do início da Guerra Fria, os objetivos americanos incluiriam a proteção do Atlântico Sul contra o tráfego marítimo soviético e a conservação da ordem interna nas repúblicas latinas.

Por seu lado, às Forças Armadas da região interessavam os armamentos modernos, o treinamento e assessoria ianques, a partir de uma aceitação da impossibilidade de evitar a hegemonia estratégica dos EUA no contexto da Guerra Fria. É bom reter, assim, que a expectativa de obter as chamadas "armas de prestígio" conviveu com um traço histórico dos militares da região: sua vocação para a intervenção interna, calcada num acentuado anticomunismo, traço esse anterior à Guerra Fria.

No primeiro quinquênio do pós-guerra, diante das exigências da reconstrução européia e do advento da revolução na China, o sistema militar continental (como de resto a própria América Latina) passou para segundo plano nas preocupações do Departamento de Estado, embora se mantivesse na pauta dos chefes militares americanos. Enquanto isso, crescia a resistência da opinião pública à manutenção da ajuda militar ao Sul em tempos de paz ${ }^{4}$. Ao mesmo tempo, a oposição no Congresso americano criava obstáculos intransponíveis aos intuitos do aparelho militar dos EUA no sentido de consolidar os laços construídos durante a guerra, sob a hegemonia americana.

Foi nesse quadro adverso que se reuniu em Petrópolis, em agosto de 1947, a "Conferência Interamericana para Manutenção da Paz e da Segurança Continental". Desse encontro, o pri-

\footnotetext{
4 Ver CHILD, 1980, p. 94. Este autor cita a oposição, nos Estados Unidos, de grupos pacifistas, socialistas e comunistas, além de setores do próprio establishment.
} 
meiro realizado no período da Guerra Fria, resultaria o Tratado Interamericano de Assistência Recíproca (TIAR) subscrito por praticamente todos os países da região ${ }^{5}$. A principal justificativa do convênio foi o princípio de que um ataque armado movido por qualquer país contra um estado americano seria considerado um ataque contra todos eles. O tratado levantou ampla onda de protestos na América Latina, com acusações de que os aliados dos EUA tinham se acorrentado à estratégia militar americana (cf. CHILD, 1980, p. 100). Apesar disso, o TIAR permitiu o avanço do Sistema Militar Interamericano e abriu caminho para a primeira série de acordos bilaterais para o estabelecimento de missões de assessoria militar ${ }^{6}$. Os americanos somente não conseguiram a criação de um Conselho Interamericano de Defesa, aparentemente considerado pelos países latinos como um excesso de controle dos EUA sobre o sistema intercontinental. Assim, o único organismo de coordenação permanente continuou a ser a já existente Junta Interamericana de Defesa (JID). Herdada dos tempos da União Panamericana, a Junta expressaria não apenas a subordinação das forças armadas latino-americanas à visão estratégica global dos EUA, como a autonomia dos mecanismos militares dentro dos quadros da União Panamericana ${ }^{7}$.

Mas, no começo dos anos cinqüenta, a eclosão da Guerra da Coréia tiraria a aliança militar interamericana da inércia relativa do pós-guerra. $\mathrm{O}$ maior conflito convencional do período da Guerra Fria, a Coréia fez caírem nos EUA as resistências anteriores à aprovação do Mutual Security Act, que entra finalmente em vigor em $1951^{8}$. Com

\footnotetext{
5 As exceções foram a Nicarágua e o Equador, devido a golpes recém-ocorridos que impediram a presença de seus delegados (cf. MECHAM, 1961, p. 281).
}

6 O Brasil saiu na frente, a 15 de agosto de 1948, com o convênio que resultaria na criação da Escola Superior de Guerra (cf. MECHAM, 1961, p. 297 e segs.).

7 "De fato, a única ligação oficial da União Panamericana com a Junta de Defesa é o suprimento dos fundos necessários, incluídos no orçamento da OEA" (cf. MECHAM, 1961, p.330).

8 O Mutual Security Act consolidou e unificou os vários programas de ajuda militar americana, destinando ao cargo de Diretor de Assistência Mútua, associado diretamente à Presidência, a supervisão dos programas de ajuda militar, econômica e técnica (cf. U.S. AIR FORCE, 1970, p. 5). efeito, diante da escalada nuclear e da decisão americana de fabricar a bomba de hidrogênio, os primeiros anos da década de cinquienta constituíram uma fase particularmente tensa da Guerra Fria. Dessa maneira, o segundo mandato de Truman marcou a escalada nos gastos gerais de defesa, cuja expressão legal foi o famoso documento do Conselho de Segurança Nacional, mais conhecido como NSC-68 (cf. PATERSON, 1996, p. 176 e segs.). Nesse contexto, o Sistema Interamericano de Defesa sairia fortalecido, com a aprovação pelo Congresso dos EUA do quadro jurídico que possibilitou a série de acordos militares bilaterais efetuados a partir de 1952 com todos os países da área, menos o México e a Argentina (até 1964). Houve considerável reação pública na América Latina à assinatura dos acordos. No Brasil, a situação interna retardou a sua ratificação por quatorze meses. Mas a série de convênios consolidou efetivamente o sistema de hegemonia militar continental da Guerra Fria. A partir de 1952, nas palavras de um especialista americano: “Os Estados Unidos moveram-se rapidamente [...] para uma posição de quase-monopólio da venda de armamentos e assessoria militar na América Latina [...]. Enquanto principal fornecedor de armas e assessoria, os EUA controlavam o SID (e detinham) um virtual monopólio de fornecimento de armas, treinamento e influência sobre os militares latino-americanos" (CHILD, 1980, p. 124).

Assim, no final da década, o sistema de ajuda militar envolvia: 1) missões militares americanas em dezoito países, com quinhentos e cinquienta e oito assessores das três forças ${ }^{9}$; 2) cerca de oitocentos oficiais americanos na América Latina (sem contar os militares estacionados no Panamá); 3) intenso treinamento de oficiais do Sul em bases no Panamá e nos EUA; 4) amplas vendas de material militar, a vista ou a crédito; 5) visitas regulares aos EUA por parte de oficiais latino-americanos; e 6) um comando unificado americano para a América Latina, estabelecido na Zona do Canal: o SOUTHCOM (cf. CHILD, 1980, p. 126).

Mas o sucesso da aliança não escondia incon-

9 O Exército tinha missões em todos os países da egião exceto Argentina e Haiti; a Marinha, em todas as nações com uma força naval; a Força Aérea apenas não tinha assessores na Costa Rica e República Dominicana (cf. HOVEY, 1966, p. 55). 
sistências e contradições. Fruto da mentalidade vigente na fase mais aguda da Guerra Fria e da influência do establishment militar dos EUA, o SMI permanecia vulnerável à crítica de setores minoritários mas influentes do Congresso americano. Duvidava-se principalmente da função da ajuda militar aos países latino-americanos para a defesa do hemisfério contra eventuais ataques soviéticos. Nesse sentido, havia claras discrepâncias entre a justificativa formal da aliança e seus objetivos reais. Formalmente, a ajuda militar visava duas tarefas centrais: a contribuição à defesa externa do hemisfério e a manutenção da ordem interna, de modo a prevenir situações que pudessem desviar os Estados Unidos de suas áreas de interesse estratégico prioritário. Foi essa a explicação para as transferências de armas e equipamentos sobrantes da Segunda Guerra Mundial durante os anos cinquienta.

Quanto a seu alvo e caráter efetivos, na visão do Pentágono, a ajuda militar visava sobretudo à manutenção dos laços bilaterais estreitos com os Estados-Maiores da região e da reserva de mercado bélico contra os concorrentes europeus (cf. CHILD, 1980, p. 77; e RABE, 1988, p. 55, 77, $89,107)$. Sempre houve espaço, também, para as tarefas de guerra anti-submarina no Atlântico Sul. Já do ponto de vista do Departamento de Estado, o objetivo menos confessável era o cultivo dos laços políticos com o setor mais influente dos sistemas políticos latinos, com desprezo pelas consequiências que o fortalecimento dos militares pudesse ter sobre as perspectivas da democracia na região. Assim, numa estimativa de dezembro de 1958, os especialistas em Segurança Nacional americanos avaliavam: "Apesar da crescente sensibilidade à influência nacionalista, a atitude da maioria dos corpos de oficiais latino-americanos face aos EUA é geralmente favorável. Os líderes militares mantêm provavelmente uma identificação mais estreita com os interesses hemisféricos dos EUA que a de qualquer outro grupo da América Latina" (U.S. DEPARTMENT OF STATE, 1991, p. 71).

É verdade que, nos anos cinqüenta, o peso militar da América Latina era mínimo. Numa avaliação elaborada em 1948, apenas Brasil e México tinham algum lugar nas considerações dos EUA na escala de importância estratégica das várias regiões do mundo, ainda assim como sexta prioridade entre sete categorias (cf. CHILD, 1980, p. 111). Em outro documento conjunto das forças armadas americanas datado de meados de 1948, as zonas estratégicas principais na região incluíam, entre outras, o Canal do Panamá, o Nordeste do Brasil, os poços de petróleo da Venezuela, o estuário do Rio da Prata, o estreito de Magalhães e as minas de cobre do Chile. Não por acaso, tanto o "Plano Militar Geral para a Defesa do Continente Americano" (novembro de 1951), como sua refor-mulação parcial de 1957 situam a América Latina fora do "Espaço Primário", "onde a luta pelo poder atual está ocorrendo, que se situa entre os paralelos dez e quarenta latitude norte e é ocupado pelas nações cujo território poderia servir como área de conflito armado entre o mundo livre e as nações comunistas"10. O próprio subsecretário de Estado Walter Smith reconhecia em 1954 que o teor das decisões sobre a ajuda militar colocava a região "embaixo da pilha, no que diz respeito a prioridades militares" (RABE, 1988, p. $35)$.

A conclusão óbvia era que, nos quadros da Guerra Fria, a importância da região situava-se em outro campo. Embora alguns países guardassem suas funções "na defesa de instalações militares e econômicas vitais, no desempenho de patrulhamento anti-submarino naval e aéreo, na preservação das comunicações e na produção de matérias-primas críticas e estratégicas e outros componentes de defesa econômica", parecia claro que "uma vez que um ataque direto pelas forças comunistas na América do Sul é improvável, as principais contribuições da América Latina para as nações do mundo livre se concentrariam na manutenção da ordem e na prevenção de atividades subversivas" (MECHAM, 1961, p. 334).

Nesse quadro, no total dos gastos dos Estados Unidos com ajuda militar nos anos 1950-59, a Europa ficou com cinqüenta e cinco por cento, o Extremo Oriente com vinte e três por cento, o Oriente Próximo, Sul da Ásia e África com quatorze por cento e a América Latina com um por cento (cf. U.S. DEPARTMENT OF DEFENSE, ARSD, 1960, p. 82). Entre 1949 e 1952, oitenta por cento das transferências destinaram-se ao velho continente. A partir de 1957, a ajuda à Ásia começa a subir acentuadamente, ultrapassando o total europeu no final da década, para atingir cerca de setenta por cento já em $1962^{11}$.

\footnotetext{
10 As informações para esta parte fundam-se na exposição de MECHAM (1961, p. 333) sobre o "Plano" e seus anexos: "Áreas de Importância Estratégica Específica" e "Inteligência e Contra-Inteligência”.
}

11 Para esses dados, baseio-me nos relatórios dos secre- 
Essa era a situação do Sistema Militar Interamericano quando irrompeu a Revolução Cubana. Alimentado com a transferência de material bélico obsoleto, intensamente ativo no que diz respeito à transmissão das doutrinas e métodos militares da Guerra Fria, sofisticadamente estruturado através de acordos e comissões bilaterais e programas regulares de intercâmbio, o SMI era modesto em termos dos totais da ajuda militar global americana e se debatia entre uma função de defesa cada vez mais fictícia e um papel não reconhecido de prote-ger o continente contra a infiltração comunista interna ${ }^{12}$. Esse nó seria desatado pela vitória dos guerrilheiros em Cuba. Voltemos às origens dessas mudanças no governo Eisenhower.

\section{DE EISENHOWER A KENNEDY}

Aos olhos do Departamento de Estado e do Pentágono, bastaram nove meses para que a revolução castrista deixasse de ser vista como um movimento democrático-reformista, passível de assimilação nos quadros da hegemonia americana no hemisfério. Medidas como a legalização do PC cubano, o adiamento das eleições e os julgamentos e execuções revolucionárias encarregaram-se de convencer o governo Eisenhower (1953-1960) de que Cuba vivia uma revolução mais radical. Daí para a frente a ilha foi o equivalente na Guerra Fria à "úlcera espanhola" de Napoleão no começo do século XIX. A resolução da crise dos mísseis em novembro de 1962 viria amenizar a situação, ao deixar claro para os estrategistas americanos que os limites do conflito bipolar se aplicavam mesmo aos rebeldes cubanos. Mas no distante setembro de 1959, quando Fidel Castro fez sua segunda viagem aos EUA depois da derrubada de Batista, abriu-se uma ameaça cujo limite não estava claro. Naquela altura, ao falar ao plenário das Nações Unidas, em Nova Iorque, o líder cubano responsabilizou Washington pela pobreza de Cuba e pregou o neutralismo como alternativa para os países do Terceiro Mundo (cf. RABE, 1988, p. 123-126).

Nesse quadro, no final de 1959, o governo Eisenhower definiu-se pela necessidade de inter-

tários da Defesa dos Estados Unidos entre 1948 e 1962.

12 Para um balanço interessante das funções de defesa antisubmarina e antiminas, ver FLORES (1985, p. 437-464), de resto um texto bastante esclarecedor para a história da hegemonia militar americana durante a guerra fria. romper o curso revolucionário do regime cubano. Em documento datado de 11 de novembro, o secretário de Estado Christian Herter recomendou a Eisenhower a adoção de uma política "destinada a estimular, dentro de Cuba e em outras partes da América Latina, a oposição aos rumos extremistas e anti-americanos do regime de Castro" (RABE, 1988 , p. 127). A assinatura dos acordos comerciais com a URSS, em fevereiro de 1960, apenas agravou a situação. Um mês antes, a CIA já se decidira pela derrubada de Fidel.

Foi em tal clima que, a 17 de março de 1960, o presidente Eisenhower deu sinal verde à CIA para que preparasse os planos de invasão da ilha. $\mathrm{O}$ documento que originou a decisão ("A Program of Covert Action Against the Castro Regime"), elaborado por um grupo de trabalho que reuniu homens do Departamento de Estado, do Conselho de Segurança Nacional e da Central Intelligence Agency, estabelecia os pontos fundamentais para a nova política: 1) a construção de uma oposição "responsável e unificada" a Fidel, fora de Cuba; 2) uma poderosa ofensiva de propaganda; 3) a formação de uma organização clandestina em Cuba, ligada à oposição no exílio; e 4) "a criação de uma força paramilitar fora de Cuba para futura ação de guerrilha" (RABE, 1988, p. 129).

Aqui é preciso lembrar que, no último ano do período Eisenhower, a análise da situação em Cuba iria combinar-se, no plano mundial, com uma série de acontecimentos que pareciam enfraquecer os EUA diante da URSS. Em maio, a derrubada do avião americano de espionagem U-2 pelos soviéticos arruinou o encontro de cúpula de Paris entre Ike e Kruschev (cf. WALKER, 1993, p. 133 e segs.). Em seguida, o presidente dos EUA viu-se forçado a cancelar uma viagem ao Japão, temendo manifestações antiamericanas. O pesadelo se completava com a epidemia de revoluções de libertação nacional: como resultado da fase de aguda descolonização dos anos cinqüenta, apenas no período Eisenhower, trinta nações da África e Ásia tinham se libertado de suas metrópoles.

Explica-se assim por que, no final de 1960, o chefe da CIA, Allen Dulles defendia, em memorando ao presidente, que "o espírito da revolução está lá fora, nas grandes áreas do mundo", acrescentando em seguida que os Estados Unidos estavam diante de "uma revolta dos despossuídos (have-nots), particularmente na América Latina, na Ásia e na África" (RABE, 1988, 
p.139). Nessa altura, como revelou em 1975 a investigação do Senado americano conhecida como o Comitê Church, o mesmo Dulles já autorizara as operações do coronel King da CIA, que resultariam no assassinato do líder congolês Patrice Lumumba, em fevereiro de 1961 (cf. RABE, 1988, p. 167-168; FONTAINE, 1983, p. 411-419 e 440). A CIA conseguia então o primeiro de seus dois grandes troféus da guerra antiinsurrecional. $\mathrm{O}$ segundo fez trinta anos a $7 \mathrm{de}$ outubro de 1997.

Voltando aos EUA, a campanha eleitoral de 1960 para a presidência desenrolou-se numa conjuntura externa adversa para o presidente Eisenhower e para o candidato republicano, Richard Nixon. A Guerra Fria foi um grande tema. O democrata John Kennedy empenhou-se em tirar partido da situação. Incentivado pelo tom anticastrista da grande imprensa americana, o candidato desafiante fez do combate à Revolução Cubana um dos principais lemas de campanha. Em outubro, na véspera do quarto round dos famosos debates televisados com Nixon, os assessores de Kennedy divulgaram a opinião de JFK sobre a situação na ilha: "Devemos buscar o fortalecimento das forças democráticas anticastristas, com exceção dos partidários de Batista, tanto no exílio como na própria Cuba, que ofereçam eventual esperança para a derrubada de Castro. Até aqui esses combatentes pela liberdade não tiveram praticamente nenhum apoio de nosso governo" (WICKER, 1991, p. 232-233).

A declaração e os comentários que ela gerou no debate da TV atingiram seu alvo: apresentar Richard Nixon, que não podia, obviamente, confessar os planos clandestinos em andamento, como o vice-presidente de um governo emasculado e envelhecido, incapaz de responder com a energia devida aos desafios da guerra fria. Segundo o mais recente livro sobre Kennedy, "à medida que a eleição se aproximava, Nixon começou a ficar histérico em relação a Cuba. Livrar-se de Fidel Castro, por golpe ou assassinato, pensava ele, lhe daria a presidência" (HERSH, 1998, p. 175). Por seu lado, Jack Kennedy prometia "pôr a América em movimento", removendo do poder, no caminho, os guerrilheiros caribenhos. Ao que se sabe hoje, Kennedy foi informado dos planos da CIA para a invasão de Cuba somente no final de novembro ${ }^{13}$. No começo do mês, Allen

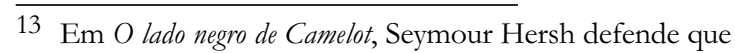

Dulles conseguira ampliar significativamente os preparativos para a operação. Ao invés de trezentos homens, o projeto incluía agora uma força de mais de setecentos, armados com equipamento pesado. $\mathrm{O}$ ataque seria precedido de incursões aéreas provenientes da Nicarágua. Nesse quadro, como afirmou Seymour Hersh, "a política americana para Cuba tornou-se a mais importante e, talvez, a mais secreta questão da campanha Kennedy-Nixon” (HERSH, 1998, p. 177).

No dia 6 de dezembro, quando foi à Casa Branca para discutir o estado das questões externas, Kennedy recebeu uma avaliação que definia Cuba como "o maior perigo para os objetivos dos EUA na América Latina” (RABE, 1988, p. 170-171). Assim, Ike deixou armada para JFK a armadilha da Baía dos Porcos. Kennedy, por sua vez, manteve Allen Dulles na direção da CIA. Quando assumiu a presidência, estava já disposto a fazer da invasão de Cuba o primeiro exemplo de uma nova era na política externa dos EUA (cf. PATERSON, 1988, p. 200 e segs.). A 20 de janeiro de 1961, o novo presidente subiu ao poder decidido a enfrentar os soviéticos nos campos do Terceiro Mundo. Segundo Richard Barnet (1972, p. 79), “Kennedy chegou à Casa Branca convencido de que a grande batalha de seu governo seria o destino do Terceiro Mundo e que tal destino seria decidido pelas atribulações da guerra de guerrilhas". Para o historiador Thomas Paterson (1989, p. 124), "a famosa ânsia de Kennedy pela ação tornou-se exagerada no caso de Cuba".

Dessa maneira, logo nos primeiros dias de seu governo Kennedy reuniu o Conselho de Segurança Nacional, que daria o sinal verde ao plano de invasão elaborado nos últimos meses do período Eisenhower. Estimulado pelo sucesso da ação golpista da CIA na Guatemala em 1954, Allen Dulles assegurou ao presidente que, mesmo sem a participação visível dos EUA (impossível de conciliar com a retórica da Aliança), o desembarque seria um sucesso. Após a primeira reunião aceleraram-se modificações no plano e escolheuse como local da ação a Baía dos Porcos (cf. PATERSON, 1989, p. 130 e segs.). A partir daí, a história da invasão da ilha em abril é conhecida. Em apenas quatro dias, a resposta cubana resul-

pelo menos três fontes, além do mafioso Sam Giancana, poderiam ter contado a JFK sobre a operação antes da eleições (cf. HERSH, 1998, 177 e segs.). 
tou na prisão de mil cento e oitenta e nove brigadistas e na morte de cento e quatorze contra-revolucionários. Na avaliação de James Patterson (1996, p. 492), consumava-se ali "uma das mais desastrosas aventuras militares da história moderna americana”. Só então Kennedy afastou Dulles.

\section{A CONTRA-INSURREIÇÃO}

Em 1949 a Revolução Chinesa foi o clarão que despertou os estados-maiores ocidentais para o desafio da guerra revolucionária. Uma década antes da Revolução Cubana a ascensão dos comunistas de Mao Tsé-tung ao poder teve imensas repercussões nos Estados Unidos. Em parte, a ânsia de ação kennedyana do início dos anos 60 deve ser entendida como resposta ao insistente refrão republicano dos anos cinqüenta: "Os democratas perderam a China!"14. Na campanha eleitoral de 1960 isso explica também a ênfase de JFK na "perda de Cuba" por Eisenhower. Outra consequiência crucial da "perda da China" foi o expurgo dos melhores especialistas em assuntos asiáticos no Departamento de Estado nos anos do macarthismo, uma das raízes da colossal incompreensão americana sobre o caráter da Guerra do Vietnã (cf. THOMSON, 1968; HALBERSTAM, 1992, p. 386 e segs.). Nesse quadro, os estrategistas americanos chegaram relativamente tarde à valorização de uma doutrina antiinsurrecional nos quadros da Guerra Fria ${ }^{15}$. Como se sabe, as primeiras teorias desse tipo foram elaboradas como resposta às lutas de libertação nacional nos domínios ingleses e franceses. A derrota francesa na Indochina, em 1954, gerou a mais articulada dessas doutrinas: a guerre

14 Durante toda a década, o dono do importante conglomerado de imprensa Time-Life, Harry Luce, filho de missionário que passara a infância na China, encarregou-se de manter aceso o tema chinês. Luce era, obviamente, republicano e deixou claro ao pai de Kennedy que vigiaria o novo governo democrata quanto a qualquer amolecimento com os comunistas da Ásia ou de outras regiões. Ver a este respeito o livro de David Halberstam, The Powers that Be, uma vívida análise dos maiores grupos da mídia americana durante a guerra fria.

15 SHY e COLLIER (1986, p. 854) atribuem o atraso americano a outros fatores como a vitória sobre a guerrilha nas Filipinas e o desprezo pelo fracasso francês na Indochina. révolutionnaire. Seria necessária a vitória de Fidel Castro em Cuba para que os americanos criassem sua versão da estratégia antiguerrilha: a doutrina da contra-insurreição.

O que nos conduz de volta à "Aliança para o Progresso" e à denúncia de Guevara em agosto de 1961. Com efeito, a idéia de combinar esforços militares com um programa de ação cívica era um dos elementos centrais da guerre révolutionnaire do Terceiro Mundo. Na síntese da doutrina francesa feita por dois insuspeitos americanos - um deles veterano da Guerra do Vietnã -, destaca-se justamente que aí os esforços militares e de guerra psicológica aparecem ao lado de um "programa paralelo de ação social e econômica (que) deve enfrentar com vigor problemas como educação, saúde pública e pobreza, os quais criavam as condições de maturação para a colheita comunista" (SHY e COLLIER, 1986, p. 953).

Não por acaso, no seu balanço das atividades no último ano do período Kennedy, o Secretário de Defesa americano iria afirmar que "a ênfase na América Latina, que forma parte integrante do esforço global da Aliança para o Progresso, tem se deslocado crescentemente para o fortalecimento da segurança interna, sem a qual pouco progresso econômico pode ser atingido ou sustentado" (U.S. DEPARTMENT OF DEFENSE, ARSD, 1963b, p. 53).

Contudo, o jovem presidente Kennedy não foi apenas um adepto fervoroso da luta pelos "corações e mentes" 16 dos povos do Terceiro Mundo. A invasão da Baía dos Porcos mostrou o ativismo do novo governo também no campo militar. $\mathrm{O}$ fracasso da aventura implicaria não num arrefecimento, mas na consolidação do entusiasmo presidencial pelo emprego das "forças especiais" no Terceiro Mundo. Assim como a doutrina da guerre révolutionnaire, a então nascente teoria da contra-insurreição dava ênfase central à reorganização as Forças Armadas, nos quadros da superação da ênfase exclusiva na guerra nuclear, que permitia o avanço comunista pelos flancos do mundo livre. Kennedy, mais uma vez, foi um entusiasta. Sobre sua mesa na Casa Branca uma boina verde das forças especiais aparecia com

16 A expressão surgiu na Malásia, como parte do esforço anti-insurrecional inglês. 
destaque; após sua morte, a escola desses regimentos em Forte Bragg recebeu seu nome ${ }^{17}$. Segundo Martin Walker (1993, p.164), o presidente democrata supervisionou pessoalmente os "uniformes, botas pessoais e armas leves, adaptadas ao novos tipos de guerra política e de guerrilha que almejava"18. Kennedy também teorizou sobre a contra-insurreição, "uma luta em muito sentidos mais difícil que a guerra [...] que ocorre todos os dias, sem alarde, em milhares de aldeias e mercados e nas salas de aula de todo o mundo. Os exércitos e os armamentos modernos servem principalmente como o escudo atrás do qual a subversão, a infiltração e uma série de outras táticas avança tenazmente [...] explorando o legítimo descontentamento e anseios populares e as armadilhas legítimas dos processos de autodeterminação" (WALKER, 1993, p. 164) ${ }^{19}$.

Assim, já no começo de janeiro de 1961 um documento do Departamento de Estado intitulado "A New Concept for Hemispheric Defense and Development" sugeria substituir a idéia da defesa coletiva do hemisfério contra um inimigo externo pelo conceito de manutenção da ordem interna. Como mostra John Child em Unequal Alliance, o Sistema Militar Interamericano ganhou fôlego e recursos. A participação da região no total da ajuda militar dos EUA ultrapassou o patamar de um por cento em que se mantivera durante os anos cinqüenta, para chegar a seis por cento em poucos anos (cf. CHILD, 1980, p. 147 e segs.).

Os discípulos de Kennedy não ficaram nada a dever a seu mentor. Um bom exemplo é Walt Rostow, professor universitário ${ }^{20}$ e chefe do escritório de planejamento político do Departamento de Estado, o mesmo funcionário que, como assessor para a Segurança Nacional, relatou a Lyndon Johnson os últimos passos da caçada a Guevara na Bolívia (cf. CASTAÑEDA, 1997, p. $430-31,440)^{21}$. O clima dos primeiros meses do

17 Ver Richard Walton, citado em PATTERSON, 1996, p. 490 .

18 Sua referência aqui é Ted Sorensen, Kennedy (New York, 1965, p. 292), um livro considerado simpático a JFK.

19 A fonte original é Public Papers of the President, 1961.

20 Sobre a íntima colaboração entre Pentágono, CIA e universidades norte-americanas, ver "Social Science and Government”, in CHILCOTE, 1994, p. 40-47.

David Halberstam (1992, p.160) atribui a Rostow a governo Kennedy aparece com clareza num discurso que Rostow pronunciou por ocasião do encerramento de mais um curso na "United States Army Special Warfare School”, em Forte Bragg. Ali, ele lembrou que o governo Kennedy começava em meio a crises insurrecionais em quatro pontos do globo: Cuba, Congo, Laos e Vietnã ${ }^{22}$. Em seguida, destacou o relatório de Kruschev à recente conferência dos partidos comunistas, realizada em Moscou, para mostrar que o apoio às guerras de libertação nacional era o alvo básico da nova estratégia soviética. Para Rostow, o comunismo podia ser visto como "uma doença da passagem para a modernização" 23 . Diante dessa ameaça, o interesse maior da política externa americana seria o de defender os países ameaçados pela estratégia de submissão soviética, a fim de "manter um ambiente no cenário mundial que permita a nossa sociedade aberta sobreviver e florescer".

Os atentos alunos ouviram a seguir que entre as muitas responsabilidades de seu lugar como potência mundial, os Estados Unidos tinham que aprender a "conter a guerra de guerrilhas, se possível e enfrentá-la, se necessário", a fim de aniquilar essa "doença internacional [...], planejada, iniciada, apoiada e comandada de fora das nações independentes". Num tom ligeiramente apocalíptico o professor anunciou em Forte Bragg que não haveria paz no mundo se a comunidade internacional aceitasse a ascensão de um governo originário de guerrilhas. A interferência em nações independentes devia ser equiparada à agressão externa convencional. Por fim, num golpe de oratória, ele recomendou a seu público militar que lesse com atenção os trabalhos de Guevara e Mao Tsé-tung: "a orquestração de tropas profissionais, milícias e grupos de guerrilheiros é um jogo antigo,

primeira comemoração da morte de Guevara em Washington. Segundo ele, o assessor chamou seus auxiliares a seu escritório e anunciou: "Senhores, tenho notícias muito importantes. Os bolivianos executaram o Che. Finalmente eles pegaram o filho da puta. O último dos guerrilheiros românticos".

22 "Guerrilla Warfare in the Underdeveloped Areas", reproduzido in RANSOM, 1965, p. 507-513. Para uma apreciação do agravamento da situação mundial nessa fase, ver também U.S. DEPARTMENT OF DEFENSE, ARFY 1962 e 1963, p. 48-49.

23 Ver uma síntese da teoria da modernização em SMITH, 1996, p.144-147. 
cujas regras podem ser estudadas e aprendidas". Infelizmente, o fervor contra-insurrecional kennedyano encontrou uma audiência castrense ainda mais atenta e favorável na América Latina dos anos sessenta. Nem mesmo os próprios militares americanos mostraram-se tão seguros da eficácia da novo figurino estratégico.

Comecemos pela própria natureza do material bélico que passou a ser exportado nos pacotes de ajuda militar americana. Neste aspecto, como percebeu um analista, "a mudança marcava a passagem de tanques, navios pesados e aeronaves de alto desempenho, para caminhões e blindados leves, material para patrulhas pequenas e aviões de combate e transporte multiuso e relativamente lentos" (CHILD, 1980, p.149). Os documentos oficiais americanos passaram a destacar a nova racionalidade da ajuda: "O custo total de uma companhia de controle de tumultos com duzentos e vinte e cinco homens, totalmente equipada com mochilas pessoais, gás lacrimogêneo, cassetetes, armas de mão e um carro-tanque para dispersar multidões com tinta indelével chega a apenas US\$ cinqüenta e oito mil dólares" (RABE, 1989, p. 118).

É difícil pensar na utilidade bélica de marcar tropas inimigas com tinta indelével. Tratava-se obviamente de material não adequado à defesa externa. Paralelamente a essa mudança de caráter, surgia na política americana uma nova unanimidade quanto à utilidade da ajuda militar. Como afirmou Stephen Kaplan, "no começo dos anos sessenta, existia uma forte coalizão no Executivo favorável à transferência de itens como helicópteros, caminhões, jipes e armas leves, além de equipamento de comunicações" (BECHMAN e KAPLAN, 1978, p. 415).

Assim, somente no ano fiscal de 1963, as equipes móveis das Forças Especiais na América Latina aumentaram $100 \%$, no quadro da crescente consciência na região "de que a ação cívica militar e operações de contra-insurreição de perfil lento estão entre as exigências militares mais prementes". Vinculada ao Exército dos EUA, a Escola das Américas passou a ser o principal centro reprodutor dessas orientações (cf. U.S. DEPARTMENT OF DEFENSE, ARSA, 1964, p.129-30, ver Anexo a este artigo). Finalmente, em 1965, no contexto da nova fase do envolvimento americano no Vietnã, depois da chamada resolução do Golfo de Tonkin, que deu ao Executivo carta branca para realizar operações na área de conflito, o relatório anual do Exército explicava a tendência de especialização regional das Forças Especiais: "As Forças Especiais para a América Latina, por exemplo, organizaram e forneceram equipes mó-veis de treinamento em guerra especial para dezes-sete países latino-americanos", compreendendo "instrução tática de contra-insurreição para as forças armadas dos países anfitriões e treinamento em operações psicológicas, ação cívica, inteli-gência de combate, comunicações, manutenção de veículos sobre rodas, treinamento tático de pequenas unidades e preparação de programas de instrução em contra-insurreição" (U.S. DEPARTMENT OF DEFENSE, ARSA, 1965, p.131).

Depois do assassinato de Kennedy, seu sucessor Lyndon Johnson iria abandonar o discurso reformista kennedyano para enfatizar apenas o aspecto militar da contra-revolução como alvo central da hegemonia americana na América Latina $^{24}$. A nomeação de Thomas Mann para os cargos de coordenador da "Aliança para o Progresso", assistente especial do presidente e secretário de Estado adjunto para assuntos interamericanos selou a sorte do programa. Mann, funcionário do Departamento de Estado, texano como LBJ e especialista em América Latina, definiu Cuba como um "câncer" no hemisfério (cf. TULCHIN, 1994, p. 219). Nos meses subseqüentes, segundo o historiador Walter LaFeber, "metade do programa de Kennedy fora desmantelado. O apoio econômico, mas não a ajuda militar, caiu com o crescimento das necessidades advindas da Guerra no Vietnã". O anticomunismo passou a ser o alvo único da política governamental. Foi esse o contexto em que se deu o envio dos vinte e dois mil soldados americanos à República Dominicana, em abril-maio de 1965. Para LaFeber (1983, p. 156-159), no final dos anos sessenta sobraram da Aliança os seus elementos mais perigosos, entre os quais "a dependência frente aos militares treinados e supridos com recursos americanos para manter a ordem em sociedades inquietas".

\section{A HERANÇA DEMOCRATA}

O historiador parece tocar aqui no ponto mais importante. Trinta anos depois da morte de Che

\footnotetext{
24 Para um relato sintético e atraente das mudanças ocorridas com a substituição de Kennedy por Johnson, ver HALBERSTAM, 1992, p. 430 e segs.
} 
Guevara, hoje parece claro que, apesar do Vietnã, não seriam as Forças Armadas dos EUA os principais alvos do entusiasmo kennedyano pela contra-insurreição. Ao contrário, a guinada estratégica de Kennedy — já anunciada nos últimos meses de Eisenhower - condicionou em escala colossal a estrutura e o preparo, as doutrinas e o material bélico das forças armadas latino-americanas, fornecendo uma justificativa externa à função histórica que vinham desempenhando há décadas. Nos Estados Unidos, as Forças Especiais foram concebidas desde o início como unidades pequenas e, como indica o próprio nome, "especiais" 25.

Com isso, não se pretende negar o vendaval temporário que tomou conta por algum tempo do aparelho de Estado americano. Entre outras medidas, vale destacar a criação, nas primeiras horas do novo governo, do Grupo Especial Interdepartamental para a Contra-Insurreição com o propósito de "assegurar unidade de esforços e o emprego de todos os recursos disponíveis com a máxima eficácia, no sentido de impedir e resistir à insurreição subversiva e formas correlatas de agressão indireta em países amigos" (apud NEWMAN, 1992, p. 168; RABE, 1989, p.11718).

Já o relatório do Secretário do Exército referente a 1961-1962 continha pela primeira vez um subtítulo "Guerra Especial", para definir a importância da capacidade bélica contra a "ameaça de atividades de insurreição, subversão e guerrilha de inspiração comunista". Mencionando manobras de treinamento em várias partes dos EUA e a criação de uma Diretoria de Guerra Especial, o texto afirma que as Forças Especiais do Exército mais do que duplicaram no período de um ano. Segundo o mesmo relatório, Forças Móveis Especiais foram enviadas ao Sudeste Asiático, América Latina e Oriente Médio e o treinamento de oficiais latino-americanos em centros militares dos EUA e da Zona do Canal incluiu habilidades em artilharia, engenharia e manutenção, além de ações castrenses de "ação cívica" (cf. U.S. DEPARTMENT OF DEFENSE, ARSA, 1962a, p. 100 e 173). Também a Marinha criou unidades especiais, conhecidas como SEAL (Sea, Air, Land), STATS (Seabee Technical Assistance

25 Devo esta observação ao coronel Geraldo Cavagnari do Núcleo de Estudos Estratégicos (NEE) da Unicamp.
Teams) e MTTs (Mobile Training Teams), "para trabalhar com forças unificadas e autóctones em várias partes do mundo", ao mesmo tempo em que aperfeiçoava o treinamento em línguas estrangeiras (cf. U.S. DEPARTMENT OF DEFENSE, ARSN, 1962b, p. 204 e 219).

O relatório do Exército para o mesmo período mostra que as Forças de Guerra Especial aumentaram seis vezes no espaço de pouco mais de um ano e meio, passando a contar com nove mil homens, divididos em três escalões diversos: 1) Forças Especiais móveis, “consistentes na maior parte de aviação, engenharia, assuntos médicos e civis, inteligência, guerra psicológica e polícia militar"; 2) forças de objetivo geral nos comandos de ultramar; e 3) forças estacionadas nos Estados Unidos (cf. U.S. DEPARTMENT OF DEFENSE, ARSA, 1963a, p. 127). A partir de 1964, agora no governo Lyndon Johnson, as Forças Especiais foram reorganizadas em sua estrutura e equipamento, para aprimorar capacidades de logística e comunicação. Uma companhia aerotransportada plena de Forças Especiais foi criada nos EUA e companhias menores foram destinadas ao Oriente Médio e à América Latina.

No entanto, análises recentes têm chamado a atenção para o fato de que essas mudanças não representaram a efetiva conversão do imenso aparelho militar americano à estratégia da contrainsurreição. Mesmo no Vietnã, laboratório de inúmeras das iniciativas contra-insurrecionais, há indícios bastante fortes da resistência dos militares dos EUA a subordinar as tarefas da guerra clássica a uma teoria contra-insurrecional que exigiria uma articulação heterodoxa entre o político e o militar. Nas palavras de dois analistas americanos, "o establishment do Exército dos EUA desconfiava de um grupo treinado para operações irregulares e o estranhamento final ocorreu quando as unidades de Forças Especiais passaram a atuar em estreito contato com a Central Intelligence Agency. A detenção e prisão pelas autoridades do Exército de um comandante das Forças Especiais no Vietnã indicam o grau em que mesmo o aparelho militar americano foi incapaz de unificar sua estratégia contra-revolucionária. Técnicos e assessores militares americanos junto às Forças Armadas do Vietnã do Sul aceitavam sua missão em boa consciência, mas assumiam que os assuntos políticos - o coração da guerra revolucionária — não eram sua responsabilidade" (SHY e 
COLLIER, 1986, p. 855).

Outros autores apontam na mesma direção: “o aparelho militar não levou a contra-insurreição a sério e o esforço do governo no Vietnã foi tudo, menos unificado. No seu incisivo trabalho The Army and Vietnam, Andrew Krepinevich capta a essência do problema do Exército com a contrainsurreição: esse tipo de conflito desafiava os próprios fundamentos sobre os quais repousava a visão do Exército sobre a guerra" (NEWMAN, 1992, p.169).

Assim, parece claro que a guinada na doutrina militar no final dos anos cinqüenta afetou muito menos as Forças Armadas americanas que as da América Latina. Em palavras mais simples, tratase de um caso típico de aplicação do ditado "faça o que eu digo mas não faça o que eu faço". Enquanto apenas uma parcela da organização militar americana passou a se dedicar à contrainsurreição, na América Latina a doutrina antiinsurrecional patrocinou uma efetiva reconversão às tarefas de "guerra" interna.

É verdade que as doutrinas e métodos franceses e ingleses já tinham anteriormente penetrado nos comandos e nos setores de informação de vários aparelhos militares da região. No caso do Brasil, alguns militares apontaram para o fato de que a mais importante influência doutrinária na luta antisubversão foi a guerre révolutionnaire ${ }^{26}$. Nesse sentido, o general Otávio Costa lembrou recentemente que os teóricos franceses ofereceram uma alternativa estratégica às Forças Armadas brasileiras, até então incapazes de encontrar uma função no cenário de grande conflito nuclear da guerra fria. Conforme ele lembra, referindo-se aos anos cinqüenta, "nesse momento, estávamos perplexos, sem saber que direção tomar [...], o

26 A intervenção do coronel Geraldo Cavagnari (NEE/ UNICAMP), no seminário em que expusemos a primeira versão deste artigo, levou-nos a pesquisar melhor este ponto. Então, ele afirmou que a influência doutrinária francesa era muito forte nos anos cinqüenta, bastando conferir as revistas militares do período. Cavagnari negou que mais de sete mil oficiais brasileiros houvessem tido treinamento nos EUA entre 1950 e 1975 (dados americanos), e sugeriu que a pesquisa no Almanaque do Exército comprovaria seu argumento. Em sua análise, os países do Cone Sul foram usuários menores da Escola das Américas. Nos anos setenta, o filme A Batalha de Argel, de Gillo Pontecorvo, era considerado, nas Forças Armadas brasileiras, uma verdadeira lição prática e visual da aplicação bem-sucedida da guerre révolutionnaire. que fazer? Para onde ir? Para que guerra devemos preparar-nos?" Sua resposta é esclarecedora: "Então começamos a tomar conhecimento de novas experiências: a da guerra interna na Grécia, das guerras da França na Indochina e na Argélia, e até mesmo do problema dentro do próprio território metropolitano francês, com De Gaulle às voltas com violentas reações internas. Nessa ocasião, a literatura militar francesa [...] foi nossa fascinação [e] apesar da influência americana, começa a refletir essa experiência colonial e metropolitana, começa formular um novo tipo de guerra. Era a guerra infinitamente pequena, a guerra insurrecional, a guerra revolucionária" (D'ARAÚJO, SOARES e CASTRO, 1994b, p. 77-78).

Nesse quadro, pesquisa sobre a carreira de centenas de oficiais do Exército até 31 de dezembro de 1974 revela dados interessantes. Embora seja grande o número de oficiais que realizaram cursos nas mais diferentes áreas em centros de treinamento nos EUA - comando, engenharia, cavalaria, artilharia, radares, etc. - é relativamente pequeno o número dos que foram treinados em funções contra-insurreição. Assim, num primeiro levantamento, realizado no Almanaque do Exército (cf. MINISTÉRIO DO EXÉRCITO, 1975), que inclui as carreiras de todos os oficiais até esta data na ativa, encontramos apenas dezenove oficiais que fizeram o "Curso de Guerra na Selva especializado na Escola das Américas" (CGS, EU); dezesseis, o de "Informação para Oficiais Superiores Estrangeiros" ("Senior Foreign Officer's Intelligence Course") (Info, EU); dois, o de "Operações Psicológicas" (Opsi, EU); e finalmente, um o de "Forças Especiais, EU" (FE, EU) e também em Guerra na Selva.

Informações reveladas em 1975 pelo próprio Departamento de Defesa, válidas para o período 1950-1975, confirmam esses dados (cf. STEIN e KLARE, 1976, p. 29-31). As cifras americanas registram o treinamento de um oficial brasileiro em Forças Especiais, dois em Operações Psicológicas, além de doze outros na área de informações, em escolas militares daquele país. Outros vinte e três fizeram cursos na Escola das Américas, no Panamá: dois em Contra-Insurreição, treze em Informações, três em Operações na Selva e cinco em Interrogatórios de Informações Militares. O Almanaque do Exército não é tão explícito e não inclui o ano de 1975. Note-se, no entanto, que os totais são idênticos: trinta e oito oficiais brasileiros, 
um número relativamente reduzido. Isso não quer dizer que os números coincidam, pois os dados se referem a períodos de tempo diferentes e não incluem oficiais da Marinha e da Aeronáutica, no caso do Almanaque do Exército ${ }^{27}$.

De qualquer modo, foram relativamente poucos os militares do Exército brasileiro treinados nos EUA, sob o influxo direto da contra-insurreição. Há referências esparsas à assessoria estrangeira francesa, inglesa e alemã desde o final dos anos cinqüenta (cf. D'ARAÚJO, SOARES e CASTRO, 1994a, p. 25, 63, 67, 135, 182, 233 e 245), mas não há dados disponíveis sobre essas relações. De todo modo, a influência doutrinária e prática dos EUA ainda pode ser considerada decisiva, mesmo no caso brasileiro. Os números acima não esclarecem quantos oficiais americanos foram enviados para cá, a fim de treinar in loco especialistas em contra-insurreição. Por outro lado, o próprio Almanaque do Exército de 1975 aponta um expressivo crescimento nos cursos de Guerra na Selva, ministrados em território brasileiro (por brasileiros ou americanos, não se sabe). Também não se deve esquecer que, até meados dos anos

27 Para um raro depoimento de um oficial que fez o curso no Panamá, ver o relato do brigadeiro João Paulo Moreira Burnier em D'ARAÚJO, SOARES e CASTRO, 1994a, p. 182-184. sessenta, houve exportação significativa de material bélico especializado para o Brasil. Ao lado disso, as atividades de ajuda à polícia política eram intensas, como prova a presença de Dan Mitrione em Belo Horizonte, depois executado pelos tupamaros no Uruguai. Por fim, como mencionamos, ao citar um documento do Departamento de Defesa de 1962, cursos de "artilharia, engenharia e manutenção" podiam estar relacionados à contrainsurreição.

\section{CONCLUSÃO}

Assim, de um modo ou de outro, ainda que sem deter exclusividade, a teoria da contrainsurreição teve maciças conseqüências sobre as Forças Armadas do continente. Tudo indica que ela deixou um arranhão quase imperceptível na história das Forças Armadas dos EUA no século $\mathrm{XX}$, mas uma cicatriz profunda nos Exércitos ao sul do rio Grande. Nesse sentido, o programa de curso da Escola das Américas vigente no começo dos anos setenta, que anexamos a seguir, tira das sombras uma das fontes de inspiração das práticas de violências, assassinatos e torturas cometidas em nome da "defesa da liberdade" no Ocidente cristão durante Guerra Fria. Os historiadores não devem deixar que a memória desses processos descanse em paz. Aqui, como disse certa vez Guimarães Rosa, "o passado também é urgente”.

Recebido para publicação em maio de 1998.

João Roberto Martins Filho (pontal@ correionet.com.br)é Doutor em Ciências Sociais pela Universidade Estadual de Campinas (UNICAMP) e Professor de Ciência Política na Universidade Federal de São Carlos (UFSCar).

\section{REFERÊNCIAS BIBLIOGRÁFICAS}

BARNET, R. J. 1972. Roots of War. The Men and Institutions behind U.S. Foreign Policy. New York : Atheneum.

BLECHMAN, B. e KAPLAN, S. (eds.) 1978. Force Without War: U.S. Armed Forces as a Political Instrument. Washington, D.C. : The Brookings Institution.

CASTAÑEDA, J. G. 1997. Che Guevara : a vida em vermelho. São Paulo : Companhia das Letras.

CHILCOTE, R. 1994. Theories of Comparative Politics. Search for a Paradigm Reconsidered. 2nd ed. Boulder : Westview.

CHILD, J. 1980. Unequal Alliance : The InterAmerican Military System : 1938-1978. Boulder, Colorado : Westview.

D'ARAÚJO, M. C., SOARES, G. A. D. e CASTRO, C. 1994a. Os anos de chumbo : a memória militar sobre a repressão. Rio de Janeiro : Relume Dumará.

1994b. Visões do golpe : a memória militar sobre 1964. Rio de Janeiro : Relume Dumará. 
FLORES, M. C. 1985. O após-guerra, olhando para o futuro. In: História Naval Brasileira, vol. 5, tomo II. Rio de Janeiro : Serviço de Documentação Geral da Marinha.

FONTAINE, A. 1983. Histoire de la guerre froide : 2. De la guerre de Corée à la crise des alliances, 1950-1971. Paris : Fayard.

HALBERSTAM, D. 1979. The Powers that Be. New York : Alfred A. Knopf.

1992. The Best and the Brightest. 20th ed. New York : Ballantine Books.

HERSH, S. 1998. O lado negro de Camelot. Porto Alegre : L\&PM Editores.

HOVEY, H. 1966. United States Military Assistance : a Study of Policies and Practices. London : Pall Mall Press.

LAFEBER, W. 1983. Inevitable Revolutions: The United States in Central America. New York : W.W. Norton \& Co.

MECHAN, J. L. 1961. The United States and Inter-American Security : 1889-1960. Austin : University of Texas Press.

NEWMAN, J. M. 1992. JFK in Vietnam : Deception, Intrigue and the Struggle for Power. New York : Warner Books.

PATERSON, T. 1988. Meeting the Communist Threat: Truman to Reagan. New York: Oxford University Press.

1989. Fixation with Cuba: the Bay of Pigs, Missile Crisis and Covert War Against Castro. In: PATERSON, T. Kennedy's Quest for Victory : American Foreign Policy : 1961-1963. New York : Oxford University Press.

PATTERSON, J. 1996. Grand Expectations: The United States : 1945-1974. New York : Oxford.

RABE, S. 1988. Eisenhower \& Latin America: The Foreign Policy of Anti-Communism. Chapel Hill, The University of North Carolina Press.

1989. Controlling Revolutions : Latin America, the Alliance for Progress, and Cold War Anti-Communism. In: PATERSON, T. (org.). Kennedy's Quest for Victory: American Foreign Policy : 1961-1963. New York : Oxford University Press.

RANSOM, H. 1965. An American Foreign Policy Reader. New York : Crowell.

ROSTOW, W. 1965. Guerrilla Warfare in the Underdeveloped Areas. In: RANSOM, H. An American Foreign Policy Reader. New York : Crowell.

SHY, J. e COLLIER, T. 1986. Revolutionary War. In: PARET, P. (org.). Makers of Modern Strategy: from Machiavelli to the Nuclear Age. Princeton : Princeton University Press.

SMITH, P. 1996. Talons of the Eagle: Dynamics of U.S.-Latin American Relations. New York/ Oxford : Oxford University Press.

SORENSEN, T. 1965. Kennedy. New York : Harper \& Row.

STEIN, N. e KLARE, M. (orgs.). 1976. The Pentagon's Protégés. U.S. Training Programs for Foreign Military Personnel. NACLA's Latin American \& Empire Report, New York, X, 1, p. 1-32.

THOMSON JR., J. T.C. 1968. How could Vietnam Happen? An Autopsy. Atlantic Monthly, Boulder, CO, p. 47-53, April.

TOWNSHEND, C. 1997. People's War. In: TOWNSHEND, c.(ed.). The Oxford Illustrated History of Warfare. New York/Oxford : Oxford University Press.

TULCHIN, J. S. 1994. The Promise of Progress : U.S. Relations with Latin America During the Adminsitration of Lyndon B. Johnson. In: COHEN, W. I. e TUCKER, N. B. Tucker. Lyndon Jonhson Confronts the World : American Foreign Policy : 1963-1968. Cambridge/New York : Cambridge University Press.

WALKER, M. 1993. The Cold War : A History. New York : Henry Holt.

WICKER, T. 1991. One of Us : Richard Nixon and the American Dream. New York : Random House. 


\section{OUTRAS FONTES}

\section{Documentos oficiais}

MINISTÉRIO DO EXÉRCITO. 1975. Departamento Geral do Pessoal. Diretoria de Cadastro e Avaliação. Almanaque do Pessoal Militar do Exército. Realengo, Rio de Janeiro : ECGCF.

U.S. AIR FORCE. 1970. Evaluation Division. Directorate of Military Assistance \& Sales, Deputy Chief of Staff, S\&L, Headquarters, "Information and Guidance on Military Assistance Grant Aid and Foreign Military Sales". 12th Edition.

U.S. DEPARTMENT OF DEFENSE. 1960. Annual Report of the Secretary of Defense (ARSD), July 1, 1958 - June 30 1959, U.S. Government Printing Office, Washington.

U.S. DEPARTMENT OF DEFENSE. 1962a. Annual Report of the Secretary of the Army. (ARSA), July 1, 1961, to June 30.

U.S. DEPARTMENT OF DEFENSE. 1962b. Annual Report of the Secretary of the Navy. July 1, 1961 to June 30, 1962.
U.S. DEPARTMENT OF DEFENSE. 1963a. Annual Report of the Secretary of the Army (ARSA). July 1, 1962 to June 30.

U.S. DEPARTMENT OF DEFENSE. 1963b. Annual Report of the Secretary of Defense (ARSD). July 1, 1962 to June 30, 1963.

U.S. DEPARTMENT OF DEFENSE. 1963c. Annual Report for Fiscal Year 1962. Washington, DC, US Government Printing Office.

U.S. DEPARTMENT OF DEFENSE. 1964. Annual Report of the Secretary of the Army (ARSA). July 11963 to June 30.

U.S. DEPARTMENT OF DEFENSE. 1965. Annual Report of the Secretary of the Army (ARSA). July 1, 1964 to June 30.

U.S. DEPARTMENT OF STATE. 1991. Latin American Attitudes Toward the US. National Intelligence Estimate (NIE 80/90-58). Washington, December 2, 1958. In: Foreign Relations of the United States : 1958-1960. Vol. V, American Republics, United States Government Printing Office, Washington. 


\begin{abstract}
ANEXO
Os documentos seguintes são trechos selecionados do curso O-47, dedicado às operações de contrainsurreição urbana, no programa da U.S. Army School of the Americas. Fonte: STEIN e KLARE (1976, p. 21 e segs).
\end{abstract}

\title{
"Operações de Contra-Insurreição"
}

OBJETIVO: Propiciar a oficiais latino-americanos selecionados um conhecimento básico dos conceitos, táticas e técnicas operacionais de contra-insurreição urbana.

PRÉ-REQUISITOS: Oficiais em nível de companhia, na ativa, com interesses e responsabilidades em operações ou doutrina de contra-insurreição urbana.

\section{RESUMO DO CURSO}

1. Conceitos Básicos de Contra-Insurreição em Áreas Urbanas: Problemas nacionais que limitam o desenvolvimento; evolução e métodos de guerrilhas rurais e urbanas; fases da subversão; novas idéias da guerra urbana; combates nas cidades; explosivos improvisados.

2. Administração: Funções de Administração; princípios de organização; sistemas de informações administrativas automatizadas.

3. Segurança Física e de VIPs: Introdução à segurança/riscos físicos; sabotagem; áreas restritas; controle de pacotes e materiais; planejamento de segurança; informações e segurança de VIPs; guarda pessoal.

4. Ação Cívica: Ação cívica militar; programas de informação militar; desenvolvimento comunitário; ação cíviva e PSYOP (operações psicológicas); programas de desenvolvimento comunitário; organização para assuntos civis.

5. Operações de Informação militar em Ambiente de Contra-Insurreição Urbana: Operações de Informação; avaliação, interpretação e disseminação de informações; capacidade de informação; introdução ao interrogatório e exploração de documentos; manuseio de pessoal e documentos capturados; processos e integração; introdução à contra-informação.

6. Operações Psicológicas: Introdução às PSYOP; informação em operações psicológicas; mídia; análise de propaganda; emprego e controle de boatos.

7. Operações Aéreas em Contra-Insurreição Urbana: introdução às operações terrestres.

8. Exercício de Contra-Insurreição: exercício prático.

9. Comunismo: Teorias e estratégias; ideologia comunista e doutrina insurrecional; estratégia comunista na América Latina; agiração, propaganda e terrorismo comunistas.

\section{DESCRIÇÃO DO CURSO}

\section{CONCEITOS BÁSICOS DE CONTRA-INSURREIÇÃO EM ÁREAS URBANAS}

a. Demografia: A explosão populacional e a necessidade de controle populacional e desenvolvimento econômico; discussão de tendências e perspectivas de crescimento populacional: China, Índia e América Latina.

b. Problemas Nacionais que limitam o Desenvolvimento: Definição de inflação, desemprego, política monetária e fiscal; o dilema dos objetivos econômicos conflitantes; experiências recentes de países em desenvolvimento; aplicações na América Latina.

c. Evolução e Métodos de Guerrilhas Rurais e Urbanas: Destaques históricos do movimento de guerrilhas; desenvolvimento e situação do interesse atual pela guerrilha na área urbana; diferenças mais importantes entre guerrilha urbana e rural. 
d. Fases da Subversão: uma comparação entre as distintas teorias ou formas de expressão das fases da subversão.

e. Novas Idéias em Guerra Urbana: Elementos dos novos desenvolvimentos estratégicos e táticos na América Latina; sua aplicação na Bolívia.

f. Teoria Básica da Guerrilha Urbana: Conceitos, organização e padrões de insurreição, com ênfase no modelo de insurreição pelo mini-manual de Mariguella [sic].

g. Análise da Guerrilha Urbana dos Tupamaros: Análise das características da guerrilha urbana; táticas e objetivos do modelo tupamaro.

h. Características da Guerrilha Urbana: Organização, recrutamento, finanças, apoio logístico, segurança e táticas operacionais de guerrilha urbana.

i. Combate nas Cidades: Técnicas e fundamentos para planejar um ataque de uma área em consolidação (built-up area) em ambiente de insurreição urbana; exercício com mapas no planejamento de uma operação de consolidação.

j. Explosivos Improvisados: Tipos e utilização de explosivos improvisados; métodos de proteção de população e instalações vitais.

\section{OPERAÇÕES DE INFORMAÇÃO MILITAR EM AMBIENTE DE CONTRA-INSURREIÇÃO} URBANA

a. Orientação de Informações [...].

b. Capacidade de Informações [...].

c. Manuseio de Pessoal e Documentos Capturados: Tratamento correto de pessoal capturado para interrogatórios bem-sucedidos; evacuação; processamento de documentos.

d. Processo de Interrogatórios: Princípios e técnicas; aplicação prática de técnicas de interrogatório.

e. Aquisição e emprego de funcionários [...]. 

INSURRECTION 


\section{João Roberto Martins Filho (Universidade Federal de São Carlos)}

This article studies the impact of Cuban Revolution on interamerican relations in the period between 1959 and 1964 and, specifically, the heritage of contra-insurrection theory, exported with enthusiasm during the Kennedy government. In this period, Latin America had a prominent position in the agenda of both the State Departament and the Pentagon, something expressed in a multiplication of American military support and in the reinforcement of anti-subversive undertakings, historically performed by the military. Inside the United States, on the other hand, the employment of the socalled Special Forces was problematic, generating resistence and tension inside the Armed Forces.

KEY WORDS: Cuban Revolution; Kennedy government; Latin America; contra-insurrection; military support. 
João Roberto Martins Filho (Universidade Federal de São Carlos)

Cet article étudie l'impact de la Révolution Cubaine sur les relations interaméricaines entre 1959 et 1964 et plus particulièrement, l'héritage laissé par la théorie de la contre-insurrection, exporté avec enthousiasme sous le gouvernement Kennedy. Pendent cette période, l’Amérique Latine a figuré au centre des intérêts du Départament d'Etat et du Pentagone, ce qui s'est traduit par la multiplication de l'aide militaire Américaine et par le renforcement du rôle antisubversif, rempli historiquement par les militaires. Par contre, aux États-Unis, l’emploi des Forces Spéciales a été problématique et a engendré des resistances et des tensions au sein des Forces Armées.

MOTS-CLES: révolution cubaine; gouvernement Kennedy; Amérique Latine; contre-insurrection; aide militaire. 